\title{
Agenesis of the Gallbladder with Primary Choledochal Stones
}

\author{
El-Sayed M. Afifi Husseiny Atef Baidas Wael \\ Department of Surgery, Al-Sabah Hospital, Kuwait
}

\author{
Key Words \\ Agenesis, gallbladder • Primary common bile duct stones • \\ Congenital anomalies
}

\begin{abstract}
Objective: To report a case of true agenesis of the gallbladder (GB) with obstructive jaundice due to primary choledochal stone. Clinical Presentation and Intervention: A 66year-old woman presented with a full picture of obstructive jaundice, both clinically and biochemically. Ultrasound and endoscopic retrograde cholangiopancreatography failed to show the GB but showed dilatation of extrahepatic ducts with a stone in the common bile duct (CBD). Upon exploration, the GB was found to be absent and through a choledochotomy, the stone in the CBD was removed. Conclusion: This case shows that proper exploratory laparotomy and intraoperative cholangiography may be required to confirm absence of the GB.

Copyright $\odot 2006$ S. Karger AG, Basel
\end{abstract}

\section{Introduction}

Agenesis of the gallbladder (GB) and cystic duct with normal bile ducts is a rare anomaly with a reported incidence of 13-65 per 100,000 population [1]. Collected reviews of more than 1.5 million autopsies reported in the literature revealed only 237 cases of GB agenesis [1-7], an incidence of about 1 case in every 6,334 live births.
At the University of California, Los Angeles, USA, over a period of 32 years (1955-1987) only 12 patients were identified with both true agenesis of the GB and the cystic duct without extrahepatic biliary atresia [1]. Among these 12 patients, only 5 were symptomatic and no GB was found at surgery. Two of these 5 patients were jaundiced due to common bile duct (CBD) stone. A review of the literature showed an additional 381 cases of agenesis of the GB, 208 of which were symptomatic [1-9].

We report here 1 case of true agenesis of the GB presenting with obstructive jaundice due to primary choledochal stone.

\section{Case Report}

A 66-year-old Somali woman presented with right hypochondrial pain of 3 years' duration. Pain had become constant over the last year. There was no nausea or vomiting. She gave a history of dyspepsia and passing dark urine and pale stools. Her medical and surgical histories were irrelevant. No members of her family were known to have any similar illness. Clinically, the patient was afebrile, but jaundiced with mild tenderness in the right upper quadrant of the abdomen. Hematological tests showed mild anemia, normal white cell count and no evidence of hemolysis. The biochemical profile was within the normal range (NR) except for elevated alkaline phosphates $739 \mathrm{U} / \mathrm{l}$ (NR 50-136 U/l), total bilirubin 26 (NR 0-17 $\mu \mathrm{mol} / \mathrm{l}$ ) and direct bilirubin 16 (NR $0-$ $5 \mu \mathrm{mol} / \mathrm{l}$ ). The patient was admitted as a case of chronic calculus cholecystitis with obstructive jaundice for further workup. An ultrasound showed dilatation of the extrahepatic bile ducts. The CBD was $17 \mathrm{~mm}$ in diameter with a stone shadowing at its lower end. There was no comment on the GB. Endoscopic retrograde cholangiopancreatography (ERCP) showed the stone floating in

\section{KARGER}

Fax +41613061234

E-Mail karger@karger.ch

www.karger.com
(C) 2006 S. Karger AG, Basel

$1011-7571 / 06 / 0155-0379 \$ 23.50 / 0$

Accessible online at:

www.karger.com/mpp
Dr. M. Afifi El-Sayed

Department of Surgery

Al-Sabah Hospital

Safat 13053 (Kuwait)

Tel. +965 965 7873, Fax +965 483 6201, E-Mail graa7_nol@hotmail.com 


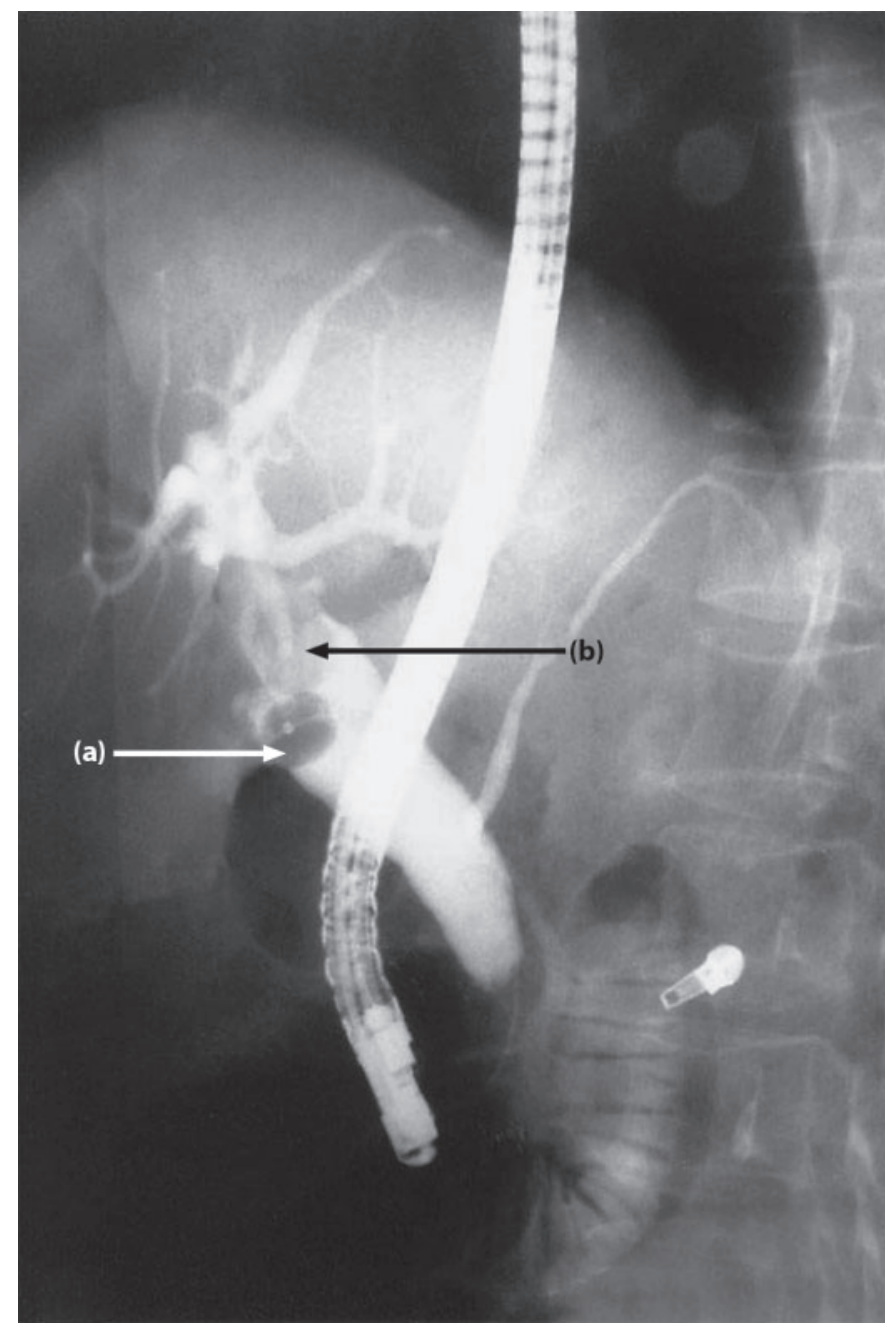

Fig. 1. ERCP showing balloon (arrow a) and the stone (arrow b). Note non-visualization of the GB.

the dilated CBD (fig. 1). Attempts at breaking the stone failed twice and during the third trial the Dormia basket capturing the stone was stuck in the $\mathrm{CBD}$ and could not be retrieved. The patient was taken for laparotomy the following day. At surgery there was no GB in its normal location. After releasing all adhesions around the biliary ducts, the supraduodenal area up to the porta hepatis was examined. An operative cholangiography through a puncture in the $\mathrm{CBD}$ was done. No GB was seen. The dilated CBD was shown with the stone captured in the Dormia basket (fig. 2). Choledochotomy was done. The Dormia basket was cut with a bone cutter and the basket, with the stone inside it, was delivered through the choledochotomy. The choledochotomy was closed primarily and the bed drained using a vacuum drain. The patient had a smooth postoperative recovery and before discharge from the hospital, a hepatobiliary radionuclide scan with technetium$99 \mathrm{~m}$-hepatoimmunodiacetic acid $\left({ }^{99 \mathrm{~m}} \mathrm{Tc}-\mathrm{HIDA}\right)$ confirmed the absence of the GB. The biochemical profile became normal and the patient was discharged home.

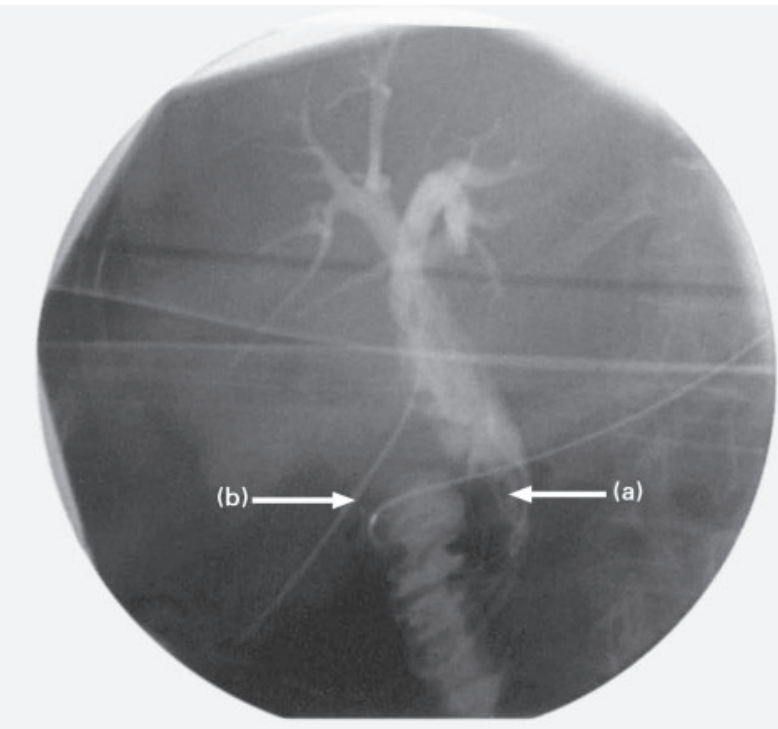

Fig. 2. Operative cholangiogram showing Dormia basket trapping the stone (arrow a) and ureteric catheter in the dilated CBD (arrow b). Note non-visualization of the GB.

\section{Discussion}

The development of the hepatobiliary system begins around the third week of gestation when the liver primordium (hepatic diverticulum) forms as an outgrowth of the endoderm at the distal end of the foregut. As the diverticulum grows, its connection with the intestines narrows and becomes the extrahepatic bile ducts. A small ventral outgrowth develops and vacuolizes, eventually forming the GB and cystic duct. Failure of this outgrowth to form results in agenesis of the GB and the cystic duct without extrahepatic biliary atresia [7].

Recent reports suggest that GB agenesis may be familial. Two of these multigenerational studies seem to indicate that the anomaly is a non-sex-linked trait with variable penetrance, although the actual incidence is not known. Other studies have also shown its familial tendency $[9,10]$.

Agenesis of the GB can present as 1 of 3 categories. Category 1 is associated with multiple fetal anomalies leading to death in the perinatal period from causes related to nonbiliary abnormalities. Bennion et al. [1] reported children in this group who had associated cardiopulmonary, external genitourinary and gastrointestinal anomalies. All 4 children died less than 1 month after birth. Forty-eight other cases have been reported [2, 4-6]. Category 2 is an asymptomatic group and the anomaly is 
discovered either at autopsy or at celiotomy for an unrelated diagnosis. Bennion et al. [1] reported 3 patients in this group who died of unrelated causes; 125 others have been reported $[2,4-6]$. Category 3 is a symptomatic group that was operated for symptoms of hepatobiliary disease and no GB was found at surgery. Two hundred and thirteen such cases have been reported [1] in this group.

The presenting symptoms of agenesis of the GB are those of hepatobiliary disorder including right upper quadrant pain, nausea, vomiting, abnormal liver function and jaundice, which was found in $2 / 5(40 \%)$ of the cases and in 74/208 (35.6\%) in the literature review. This jaundice was due to stones in the biliary tree in most cases. Our patient belongs to the symptomatic group presenting with jaundice due to a stone in the dilated CBD.

Frey et al. [6] have proposed 2 criteria to diagnose agenesis of the GB: operative findings confirmed by cholangiogram and visualization of the biliary tract by dissecting it from the duodenum to the bifurcation of hepatic ducts [6]. Based on these criteria, Richards et al. [11] reviewed 44 cases of agenesis of the GB in the English literature and found jaundice in $12(27 \%)$ but stones in only $8(18 \%)$. Ultrasonography is routinely used in cases with suspected hepatobiliary disorder. The ultrasound report may not comment on the GB, as in our case, or may report it as shrunken due to chronic cholecystitis [3]. It may show the dilated extrahepatic biliary ducts and/or stone shadow in these ducts. An ${ }^{99 \mathrm{~m}} \mathrm{Tc}-\mathrm{HIDA}$ scan, when done preoperatively, will report the absence of GB filling and attribute this to an obstructed cystic duct due to acute cholecystitis. Again ERCP, when done for a jaundiced pa- tient, will show the dilated biliary ducts and the stones if present, or report nonvisualization of the GB due to an obstructed cystic duct, as in our case.

When preoperative assessment tools fail to visualize the GB and at surgery the GB is not seen in its normal location, then it is the responsibility of the surgeon to consider agenesis of the GB and confirm this diagnosis. The operative strategy should include thorough exploration of the area from the duodenum up to the bifurcation of the hepatic ducts. Sherson and others $[9,12]$ have shown the possible ectopic location of the GB (lesser omentum - retroperitoneal - retrohepatic - falciform ligament - retroduodenal - retropancreatic). Operative cholangiography as well is essential to exclude hypoplastic or aberrantly located GB and search for stones within the biliary tree in jaundiced patients.

The importance of our case report is derived from the fact that in our relatively small population ( 2.2 million of multinational origins), there was no previously reported case of agenesis of the GB to our knowledge. Our case fulfills all the published criteria of agenesis of the GB as shown. It shows, as well, one of the rare complications of ERCP, that is failure to extract the CBD stone, and also illustrates one way to overcome this complication.

\section{Conclusion}

Proper exploratory laparotomy and intraoperative cholangiography may be required to confirm absence of the GB.

\section{References}

1 Bennion RS, Thompson JE, Tompkins RK: Agenesis of the gallbladder without extrahepatic biliary atresia. Arch Surg 1988;123: 1257-1260.

2 Stolkind E: Congenital abnormalities of the gallbladder and extra-hepatic ducts. Br J Child Dis 1939;36:115-131, 182-212, 295307.

3 Jackson RJ, McClellan D: Agenesis of the gallbladder, a cause of false-positive ultrasound. Am Surg 1989;55:36-40.
4 Monroe SE: Congenital absence of the gallbladder: a statistical study. J Int Coll Surg 1959;32:369-373.

5 McIlrath DC, Remina WH, Baggenstoss AH: Congenital absence of the gallbladder and cystic duct: report of ten cases found at necropsy. JAMA 1962;180:152-153.

-6 Frey C, Bizer L, Ernst C: Agenesis of the gallbladder. Am J Surg 1967;114:917-927.

7 Turkle SB, Swanson V, Chandrasoma P: Malformations associated with congenital absence of the gallbladder. J Med Genet 1983; 20:445-449.

-8 Baltazar U, Dunn J, Gonzalez-Diaz S, Browder W: Agenesis of the gallbladder. South Med J 2000;93:914-915.
-9 Sugrue M, Gani J, Sarre R, Watts J: Ectopia and agenesis of the gallbladder: a report of two sets of twins and review of the literature. Aust N Z J Surg 1991;61:816-818.

10 Wilson JE, Dietrick JE: Agenesis of the gallbladder: case report and familial investigation. Surgery 1986;99:106-109.

11 Richards RJ, Taubin H, Wasson D: Agenesis of the gallbladder in symptomatic adults. J Clin Gastroenterol 1993;16:231-233.

12 Sherson ND: The absent adult gallbladder. Aust N Z J Surg 1970;39:225-261. 